\section{Poor nations' crop research hurt by Japanese cutbacks}

David Cyranoski, Tokyo

With recent breakthroughs such as the draft rice genome sequence, agriculture researchers should have plenty to look forward to. But the research centres that are best placed to to tap that promise are facing a funding crisis this spring.

Japan, a major supporter of such research, is planning to cut funding for the Consultative Group on International Agricultural Research (CGIAR) by almost half, from last year’s $¥ 3.6$ billion

(US\$29 million). The CGIAR's 16 institutes form the main global network of research centres addressing the agricultural needs of poor countries.

The impact will be felt immediately at the CGIAR's prestigious International Rice Research Institute (IRRI) near Manila in the Philippines. "Japan had been our largest and most faithful donor," laments Ron Cantrell, the institute's director.

The impending cut led IRRI, at a board meeting earlier this month, to reduce staff levels by over $20 \%$ to 785 . In addition, some projects will be scaled back. The cuts will not affect the maintenance of the world's largest collection of rice germ plasm, which is kept at the institute, Cantrell says.

Other members of the CGIAR are also feeling the pinch. The International Potato Center (CIP) in Lima, Peru, expects to lose about US\$700,000 in Japanese funding and will lay off one-fifth of its staff. Research on late blight and the breeding of new pest-resistant varieties will suffer, says Hugo Li Pun, a deputy director at the CIP. Li Pun has also heard rumours that European nations are set to cut donations.

The situation is especially frustrating because so much data is now available for agricultural research, says Cantrell. "The world is bursting with new technologies," he says. "We are really on the cusp of something exciting."

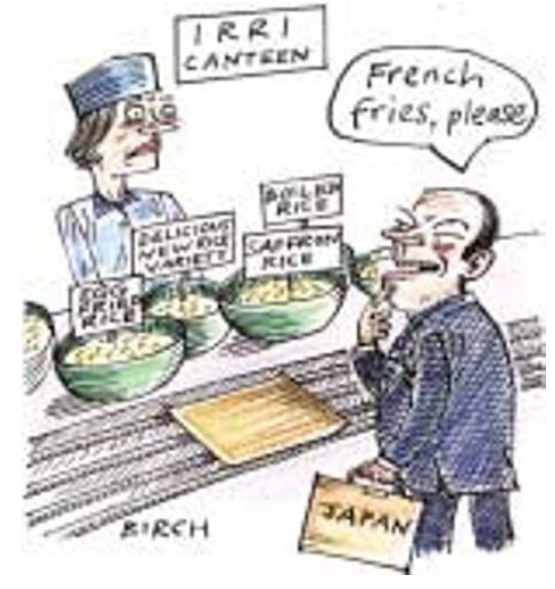

\title{
Chemistry caught in crisis catalysed by student apathy
}

David Adam, London

Researchers, politicians and teachers are warning of an impending crisis in British chemistry after a government report highlighted a dramatic collapse in the number of university students pursuing the discipline.

Chemistry - like the rest of the physical sciences - is currently struggling to attract degree students all over the world, according to professional societies and others. But the shortfall and the reasons for it in the United Kingdom were brought into sharp relief on 15 April, when the SET for Success report was delivered to the British government. It was written by a panel chaired by Oxford University physicist Gareth Roberts.

The Royal Society of Chemistry, the British professional society for chemists, says that the survival of at least a dozen university chemistry departments is in doubt because of a lack of government funding for their research programmes.

"It's very worrying and some action has to be taken," says Brian Iddon, formerly an organic-chemistry researcher at Salford University, and now Labour member of parliament for Bolton South East and a member of the Science and Technology Select Committee. "The numbers entering chemistry have simply collapsed.”

David Giachardi, chief executive of the Royal Society of Chemistry, says that recruitment difficulties are now "a worldwide problem". He says that the issue is causing concern in the United States, and the American Chemical Society confirms that the number of chemistry graduates there is in decline.

In Britain, the reasons for the trend are not hard to find. "All of my A-level chemistry class are going to university but none want to do chemistry," says teacher Zoe Thorn at Saffron Waldon County High School in Essex. More students are using chemistry as a route to vocational degrees such as medicine, she says - a situation that could worsen if the limits on medical student numbers in the United Kingdom are raised. Recent advances in molecular biology and genomics are also drawing students to life sciences and away from chemistry.

Chemistry is not the only subject in which alarm bells are ringing. Applications to study all the physical sciences have taken a nosedive in Britain and elsewhere in recent years. The total number of students entering degree courses rose by $12 \%$ between 1995 and 2000, according to the Roberts report. But those studying physics and engineering dropped by $7 \%$ and the numbers starting chemistry degrees fell by $16 \%$.

The situation could get worse before it

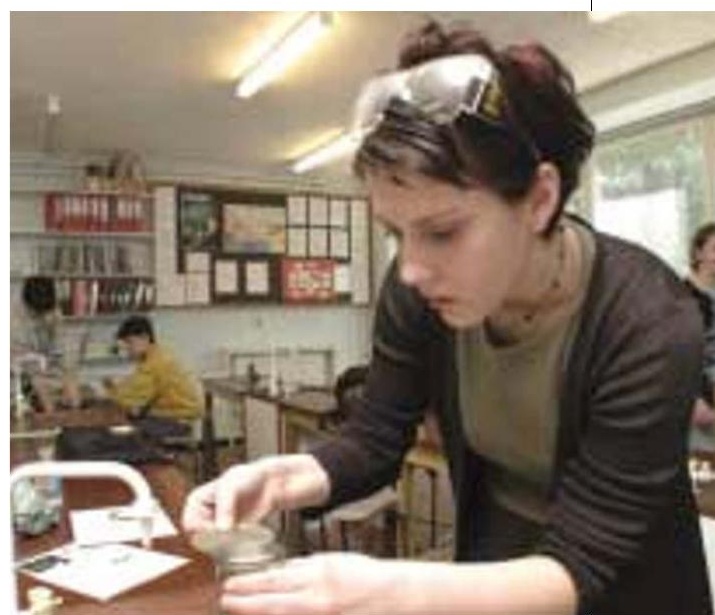

Lack of attraction: students are becoming less inclined to study chemistry at university.

gets better. Officials at the Royal Society of Chemistry privately warned the government earlier this year that the decision by the Higher Education Funding Council for England to cut funding for mid-ranking institutions (see Nature 415, 465; 2002) leaves up to a dozen chemistry departments in England vulnerable to closure.

Few observers would dispute that supply and demand should play a role in restructuring Britain's university system. But the society warns that students who choose to live at home and attend their local universities, because of the rising costs of attending, could soon find it impossible to study chemistry in certain regions, particularly in southern England.

Many heads of mid-ranking British chemistry departments contacted by Nature were concerned about falling applications and nervous about the future of their departments, but few would voice their fears openly. One department about to be subsumed by biology and sack several researchers is, its chair says, "building on its interdisciplinary strengths". Another department head, whose physical-chemistry teaching laboratory is being handed over to sports science, admits merely that it is "redistributing resources".

Chemists remain hopeful that the current retreat of students from the discipline may prove to be cyclical, rather than permanent. In Germany in the mid-1990s, for example, the number of chemistry students collapsed by some $60 \%$ - but according to Kurt Begitt, director for education and employment with the German Chemical Society, numbers have recovered after an education effort and evidence of improved job opportunities for chemistry graduates.

www.hm-treasury.gov.uk 